\title{
Mortality Factors in Severe Head Injury (SHI) at the Neurosurgical Intensive Care of the University Hospital Center of FANN (Dakar- Senegal)
}

\author{
Coulibaly Théodore Habib Maxime ${ }^{1 *}$, Dramé Ahmadou Ibrahim ${ }^{1}$, Timbiné Kalba ${ }^{2}$, Dama Mahamadou ${ }^{2}$
}

${ }^{1}$ Neurosurgical Intensive, Care of the University, Hospital Center of FANN (Dakar-Senegal)

${ }^{1,2}$ Neurosurgical Intensive, Care of the Hospital of Mali

DOI: $10.36347 /$ sasjs.2020.v06i12.003

| Received: 29.11.2020 | Accepted: 12.12.2020 | Published: 18.12.2020

*Corresponding author: Coulibaly Théodore Habib Maxime

Abstract

Original Research Article

Severe head injury is a major public health problem. About half of the deaths from traumatic causes are due to head trauma. The essential goal of early treatment is to prevent and / or limit the occurrence of secondary cerebral aggression factors of systemic origin. In developing countries, difficulties in accessing emergency diagnostic means and the availability of suitable drugs pose a problem of care. The aim of this study was to determine the factors of death of severe head injuries. This is a retrospective, descriptive and analytical study over a period of 5 years carried out in the neurosurgical intensive care unit of the UHC of FANN. It concerned all patients aged 15 and over received for SHI. The 15-44 age group was the most represented with a predominance of the male gender. Road accidents were the predominant causes followed by falls. In pre-hospitalization, more than half of the patients had received no treatment. Hemorrhagic contusion in the brain was the most common lesion seen on computed tomography. In the majority of cases was isolated SHI. In rare cases, lesions of the thorax and pelvis were associated. Factors correlated with death were: age, arterial hypotension, hypoxia and hypernatremia.

Keywords: SHI, arterial hypotension, hypoxia, hypernatremia, road traffic accident.

Copyright ( $(2020$ The Author(s): This is an open-access article distributed under the terms of the Creative Commons Attribution 4.0 International License (CC BY-NC 4.0) which permits unrestricted use, distribution, and reproduction in any medium for non-commercial use provided the original author and source are credited.

\section{INTRODUCTION}

A traumatic head injury is the consequence of accident (trauma) on the cephalic extremity. It's serious if the Glasgow score $\leq 8$ during the treatment. The severe traumatic brain injury (TBI) is a major cause of death and invalidity of young adult. If he is sometimes isolated, it's most often part of a polytraumatism. The causes are still dominated by road accidents, but the falls of old people also take a significant place. It's specificity in rapport to affected extra brain expresses itself by its great responsibility in the death causes in the polytraumatic person responsible of $68 \%$ of deaths [1-3]. The objective of this study was to identify the factors responsible of the mortality in severe traumatic brain injury in order to improve their taking care.

\section{MATERIAL AND METHODS}

It's a retrospective study, descriptive and analytic exhibited on a period of 50 months (January $1^{\text {st }}$ 2018 to December $31^{\text {st }} 2013$ ) and realized at the unity of the reanimation of neuron chirurgical service of the UHC of FANN. It concerned all adult patients (age > 15 years) admitted to intensive care for coma due to severe traumatic brain injury isolated or associated to other traumatic injuries regardless of sex and trauma mechanism during the period of our study. Were not included in our study all adult patients admitted to intensive care for other causes of coma and patients whose files were not usable. Our data were collected on the basis of hospitalization records, treatment and monitoring files. The variables measured were: sociodemographic data, clinical and para-clinical data, causes of trauma, means of transport, what to do and the factors that caused the death. The test of Chi2 and the test of FISHER were used to analyze the conditions of applicability.

\section{RESULTS}

Of the 265 traumatic brain injury admitted to intensive care during the study period 106 were severe including 95 men $(89,6 \%)$ and 11 women $(10,4 \%)$. The majority of our patients were between 15 and 44 years old $(78,30 \%)$. More than the majority of patients were from Dakar region $(51,90 \%)$ followed by regions $(47$, $16 \%$ ) and one patient was from the Gambia. The majority of patients were admitted following an public road accident $(61,30 \%)$ following by floor fall $(18 \%)$ 
and bawl (10, 30\%). In pre-hospital, non-medical transport was the most used mode of transport $(57,53 \%)$
(Table -1).

Table-1: Distribution of patients by mode of transport

\begin{tabular}{|c|c|c|}
\hline Transport & Effective(n) & Percentage (\%) \\
\hline Medical ambulance & 31 & 29,26 \\
\hline SAMU & 14 & 13,21 \\
\hline firefighter & 28 & 26,41 \\
\hline Non-medical ambulance & 16 & 15,09 \\
\hline Particular vehicle & 13 & 12,26 \\
\hline Taxi & 04 & 03,77 \\
\hline Total & 106 & 100,00 \\
\hline
\end{tabular}

Neurological examination found initial loss consciousness in 52 patients $(49,10 \%)$, a seizure in 11 patients $(10,40 \%)$, and a papillary abnormality (37, $65 \%)$. The deadline for taking charge was not specified in 77,40 (Table-2).

Table-2: Distribution of patients by the deadline of taking charge

\begin{tabular}{|l|l|l|}
\hline Deadline & Effective (n) & Percentage (\%) \\
\hline $0-2 \mathrm{H}$ & 13 & 12,30 \\
\hline $3-5 \mathrm{H}$ & 09 & 08,50 \\
\hline $6-12$ & 02 & 01,80 \\
\hline Unspecified & 82 & 77,40 \\
\hline Total & 106 & 100,00 \\
\hline
\end{tabular}

For pre-hospital care, oxygen therapy was performed in $42,90 \%$ of patients, including $18,90 \%$ with hight concentration mask and 23, 60\% with orotracheal intubation. Diazepam was the most commonly used hypnotic for Orotracheal intubation (32\%) followed by thiopental $(24 \%)$. The most used combination for sedation was diazepam and fentanyl. Half of the patients were almost admitted within the first six hours $(48,11 \%)$. More than half of the patients had a Glasgow score between $7-8$ (64 cases). Arterial hypotension was observed in $31,10 \%$ of patients. Hypoxia with an SPO2 less than 90\% was observed in
$61,32 \%$ of patients. Anemia with a hemoglobin level below $7 \mathrm{~g} / \mathrm{dl}$ was observed in $35,84 \%$. In biochemistry, hyponatremia was the most observed ionic disorder $(12,30 \%)$. Hyperglycemia was observed in $28,30 \%$ of patients. Only one patient had received a blood gas. Brain CT was performed in $90 \%$ of patients. Numerous lesions were observed: subdural hematoma (24 cases), extradural hematoma (13 cases), hemorrhagic contusion of the brain (31 cases), intra parenchymental hemorrhage (8 cases), commitments (15 cases), diffuse cerebral edema (8 cases), diffuse axonal lesion (4 cases) and cranial cerebral wounds. Other lesions were associated with severe head injury including the thorax (5 cases), pelvis (5 cases) and spine ( 2 cases). For hospital care, orotrachel intubation was performed in all admitted non-intubated patients. Thiopental was the most used drug for orotracheal intubation (22 cases) followed by diazepam and propofol in the same proportion (19 cases). Mannitol was administrated in $31,10 \%$ of patients and transfusion performed in $29,20 \%$ of patients. The surgical procedure was performed $(33 \%)$ within an unspecified time frame $(78,30 \%)$. A mechanical thromoprophylaxis was performed $(15,10 \%)$. During the hospitalization, many secondary brain attacks of systemic origin had occurred of which the most observed were hypotension $(49,05 \%)$ and hyperthermia $(47,16 \%)$ (Table-3).

Table-3: Distribution according secondary brain attacks of systemic origin during hospitalization

\begin{tabular}{|l|l|l|}
\hline Secondary brain attacks of systemic origin & Effective $(\mathbf{n})$ & Percentage $(\%)$ \\
\hline Hypotension & 52 & 49,05 \\
\hline Hypertension & 16 & 15,09 \\
\hline Hypoxia & 25 & 23,58 \\
\hline Hyperglycemia & 38 & 35,84 \\
\hline Hypernatremia & 15 & 14,15 \\
\hline Hyponatremia & 25 & 23,58 \\
\hline Hyperthermia & 50 & 47,16 \\
\hline Anemia & 38 & 35,84 \\
\hline
\end{tabular}

Amines were used in $21,70 \%$ of patients. The most common combination used for sedation was diazepam and fentanyl. Pneumophathia acquired under mechanical ventilation was the most frequent infectious complication $(15,09 \%)$ with two isolated germs : Klebsiella pneumonae and Pseudomonas aeruginosa. 
The mean duration of sedation was 11,77 days with extremes ranging from one to 13 days. The average duration of orotracheal intubation was 6,62 days with extremes ranging from one to 18 days. The tracheotomy was performed in 9,43 of patients and this after 13 days of hospitalization. More than half of the patients died $(69,80 \%)$ and the majority of deaths occurred after the $48^{\text {th }}$ hour $(71,60 \%)$.

\section{Mortality according to hypernatremia}

Death is correlated with hypernatremia with a statistically significant difference $(\mathrm{p}=0,0229)$ (Table-4).

Table-4: Mortality according to hypernatremia

\begin{tabular}{|l|l|l|}
\hline Hypernatremia & Death & P-value \\
\hline Yes & 74 & 0,0229 \\
\hline No & 32 & \\
\hline
\end{tabular}

\section{Mortality according to age}

Death is correlated with age with a statistically significant difference $(\mathrm{p}=0,0009)$ (Table-5).

Table-5: Mortality according to age

\begin{tabular}{|c|c|c|}
\hline Age & Death & P-value \\
\hline YES & & \multirow{5}{*}{0,0009} \\
\hline $15-44$ years & 54 & \\
\hline $45-59$ years & 14 & \\
\hline$>60$ years & 6 & \\
\hline $\mathrm{NO}$ & 32 & \\
\hline
\end{tabular}

Mortality based on arterial hypotension and hypoxia All the patients with board of arterial hypotension and hypoxia died.

\section{DISCUSSION}

In our series, the majority of our patients were young subjects with an age between 15-44 years $(89,6 \%)$. Our result is close to certain series [4, 5] which had reported that traumatic brain injury mainly affected young subjects with ages varying between 15 25 years.

This high frequency of SHI in young subjects can be explained by the fact that they were more exposed to road accidents. In our study, the male gender was most affected $(89,6 \%)$. This could be explained by the fact that men perform more activities that expose them to head trauma than women. Several authors $[4,6$, 7], had reported this male predominance. More than half of our patients came from Dakar $(51,90 \%)$. In our study, road accidents were the predominant cause of serious head injuries $(61,30 \%)$ followed by falls with $18 \%$. Our results were close to those of Tiret et al., [8] who observed that $60 \%$ of SHI were due to road accidents and $33 \%$ were due to falls. Same observation with Aguèmon AR [9] with $86 \%$. Unlike Servadei et al., [10], falls and aggressions were more responsible for SHI with $72 \%$ to $47 \%$ respectively. The increase in accidents on public roads is due to poor condition of vehicles and certain roads, excessive speed and also overload. In our study the neurological examination focused on the Glasgow score, the state of the pupils and the occurrence of initial loss of consciousness. In literature [11] the initial examination showed not only the Glasgow score (GCS) but also the mean arterial pressure (MAP) and the arterial saturation in $\mathrm{O}_{2}$. This observation was different from ours. Papillary abnormalities associated with initial loss of consciousness were observed in $37,65 \%$ and 49,10 , respectively. Our results were different from those of MALEOMBHO JP [12] in Ivory Coast, which found $50 \%$ papillary anomaly. Convulsions and vomiting were observed in $10,40 \%$ and $18,90 \%$ respectively. In the literature $[13,14]$ we found $85,9 \%$ and $90 \%$ respectively of cases of convulsion. These results exceeded by far our results. Our results were not comparable to those of Y. BANDE [15] in Burkina Faso which had found $50 \%$ of signs of intracranial hypertension in particular nausea, vomiting and headache. In the majority of cases, the time to prehospital taking charge was not specified $(77,40 \%)$. Orotracheal intubation was performed in $23,60 \%$ and 18,90 had received oxygen therapy with a mask. $84 \%$ of the intubated patients were sedated. The effects of orotracheal intubation with mechanical ventilation on the outcome of patients with SHI had been evaluated in a study of 600 patients [4]. The authors had observed over successive periods an increase in the proportion of patients intubated, ventilated and sedated for transfer, a reduction in the frequency of hypoxia on arrival and an improvement in the outcome of the patients $[14,5]$.

The first objective of pre-hospital intensive care is to fight against hypoxemia and hypercapnia. Thus, any traumatic brain injury with a Glasgow score less than or equal to 8 must benefit from endotracheal intubation and controlled ventilation with continuous monitoring of arterial saturation in $\mathrm{O}_{2}$ and $\mathrm{PETCO}_{2}$ [16]. In our study, the drugs used for orotracheal intubation were the combination of diazepam + suxamethonium and thiopental + suxamethonium with respectively $32 \%$ and $24 \%$. According to some authors [16] for anesthetic induction in these patients at risk (full stomach, unknown history, sometimes precarious hemodynamic state), etomidate is the most suitable hypnotic and to date suxamethonium remains the reference curare. Maintenance of sedation is carried out with an morphine hypnotic association (fentanyl). More than half of our patients $(57,53 \%)$ were admitted to hospital by unsafe transport. This finding was close to that of Cissé N [17] who found 69,7\%. Medical transports have greatly contributed to the speed of diagnosis and therefore to the quality of treatment of SHI [6]. In our study the SAMU, which is a structure specializing in the transport of these cases, intervened 
in 13,21 of the cases. This low intervention rate of this structure is due to its ignorance by the population. Nearly half of our patients were admitted to hospital within the first six hours, either $48,11 \%$. In the literature [11] the average time to arrival at the hospital was $2 \mathrm{~h} 55 \pm 1 \mathrm{~h} 40$. On admission $77,36 \%$ of our patients had papillary abnormalities, the most observed of which was mydriasis $(48,10 \%)$. Our result was close to that of Coulibaly M. [13] with $84,50 \%$. Arterial hypotension was observed in $31,10 \%$ of our patients and $19,80 \%$ presented hypotension. Our result was far from that of ETORI [18] who found a high rate of hypotension (90). Some studies report that low blood pressure is usually associated with another lesion and this hypotension is deleterious [4]. On the other hand, in the studies of Coulibaly M. [13], SIEYAMDJI [19] and TRAORE M. [20], it is the rate hypertension which was higher with respectively $25 \%, 30 \%$ and $50 \%$. More than half of our patients were hypoxic, i.e. $61.32 \%$. Our result was close to some studies [14, 19]. Anemia was observed in $35,84 \%$ of our patients. Our result was close to that of Coulibaly M. [13] who found 42,2\% anemia but far behind that of El Hadiri in Morocco [21] who had $66,70 \%$ hyponatremia was the most observed ionic disorder in our study at $12,30 \%$. The most observed glycemic disorder was hyperglycemia. Hyperglycemia is an aggravating factor in brain damage and glucose fluids are contraindicated during the first hours of resuscitation [22]. Blood gases were performed only once in our study. This observation was partly due to the unavailability and the difficulty of carrying out this examination. Almost all of our patients had received a brain scan, i.e. $90 \%$. The scanner is essential for the lesion assessment. It's sometimes the only available element of assessment of an emergency intracranial hypertension. Our result was close to that of NABOULOUM [23] in whom the scan was systematically performed in all his patients. On the other hand, our result far exceeded that of Aguèmon AR [9] who had found $7 \%$ completion of the scanner. Hemorrhagic cerebral contusions were the most frequent lesions in our patients followed by subdural hematoma with $16,80 \%$ and $11,60 \%$ respectively. Our results were comparable to those of Coulibaly M. [13] who found $18 \%$ hemorrhagic contusions. In 7,40\% of our patients, the CT scan performed was normal. This result was similar to that of Audibert G and al [24] who found $13 \%$ of patients with a normal CT scan. In our study 88,70 were isolated SHI. In the remaining $11,30 \%$ cases, the associated lesions were dominated by trauma to the thorax and pelvis in the same proportion $(4,70 \%)$ followed by trauma to the spine with $1,90 \%$. This finding was comparable to that of Cissé N. [17] who reported that thoracic trauma was associated in 53\% of cases, followed by spinal trauma with $23,5 \%$. On the other hand, our results were in contradiction with those of Bruder N [25], which reports that the risk of cervical spine injury in head trauma reached $8 \%$. This fact would certainly be explained by the proximity of the cervical region to the cephalic region. Orotracheal intubation was systematically performed on admission in all our patients who were not intubated and then they were put on controlled ventilation. This finding was comparable to that in the literature $[15,26]$ with $65,5 \%$ and $60 \%$ of cases of Orotracheal intubation on admission, respectively, in patients with a Glasgow score $<8$. Some studies have shown the benefit of early tracheal intubation in the prevention of morbidity associated with SHI [27]. Thiopental and succinylcholine were the most widely used drugs for Orotracheal intubation, at $27,20 \%$. According to several studies [17,5] thiopental was the most used drug at induction in the majority of cases. Our result is super imposable on these results. Moreover, according to Audibert G and al [28], the choice can be made between thiopental or etomidate depending on the hemodynamic state of the patient. In severe TBI, the combination of etomidate succinylcholine is recommended [24]. Arterial hypotension markedly worsens cerebral filing with $0,9 \%$ saline and hydroxyl-ethyl-starch [16]. Sedation was assured in $38,68 \%$ of patients by diazepam and fentanyl, the mean duration of this sedation was 11,77 days with extremes of one to 13 days. The combination of a hypnotic and morphine was the most frequently used technique. The high use of the combination diazepam-fentanyl, would be due to its low cost and its accessibility. The transfusion was performed in $29,20 \%$ of our patients within the first 24 hours. According to the literature [29, 30], the clan transfusion threshold ( 7 to $8 \mathrm{~g} / \mathrm{dl}$ ) probably needs to be raised in certain patients with severe cerebral aggression. A recent review of clinical and experimental studies [30] carried out in neuro-intensive care patients had shown that anemia up to $7 \mathrm{~g} / \mathrm{dl}$ was well tolerated without a history, that the transfusion worsened the prognosis in terms of mortality, disability and length of stay. Only $15,10 \%$ of our patients had received mechanical thromboprophylaxis. Mannitol was used in $31,10 \%$ of patients. Our result was different from some studies $[31,32]$ in which mannitol was used in all patients. Several studies had shown that mannitol was the most classic means of obtaining cerebral relaxation [24, 25]. Until recent years, it was clan to recommend the infusion of low doses of mannitol $(0,5 \mathrm{~g} / \mathrm{kg})$. The surgical procedure was carried out in $33 \%$ of patients and this within an unspecified time frame in the majority of cases, i.e. $78,30 \%$. The evacuation of hematoma was the most performed gesture. Our result was different from those of ETORI P [18] in 1999 at the university hospital center of Point-G and NABOULOUM [23] in Burkina Faso which found respectively $3,70 \%$ and $17,5 \%$ of performing a surgical procedure. Arterial hypotension was the most observed secondary brain attacks of systemic origin (49,50\%) followed by hyperthermia $(47,16 \%)$. Hypotension and hypoxia were the most common, respectively $28,6 \%$ of cases in the study by Cissé N. [24]. These results were different from ours. Both secondary brain attacks of systemic origin (hypotension and hypoxia) are particularly common. However, several studies had 
emphasized their importance [25] and had reported high mortality in patients with both. Secondary brain attacks of systemic origin management must be a priority in pre-hospital care. Secondary brain attacks of systemic origin are decisive in the survival prognosis of patients. Among the complications encountered were glycemic disturbances, hemodynamic instability and septic shock which would probably be due to the registered pneumonia. Hyperglycemia should also be sought, blood glucose greater than $1,8 \mathrm{~g} / \mathrm{l}$ must be treated, with targets of 1,08 to $1,44 \mathrm{~g} / \mathrm{l}$, hyperglycemia leads to cerebral ischemia [33]. Klebsiella pneumonae and pseudomonas aeruginosa were the germs found in the same proportion, 50\%. However, no study had made case of germs responsible for infectious complications. Amines were used in $21,70 \%$ of patients and the most used was adrenaline. The average duration Orotracheal intubation was 6,62 days with extremes ranging from one to 18 days. Our result was close to that of Cissé N. [17] in whom the mean duration of the Orotracheal intubation was to allow very rapid weaning from ventilator. More than half of the patients died either $69,80 \%$ and more than half o the deaths occurred after 48 hours either $71,60 \%$. In our study, all of the deceased patients presented with a picture of arterial hypotension and hypoxia. Death was correlated with age with a statistically significant difference $(\mathrm{p}=0,0009)$. The part of hypernatremia in mortality is explained by the severity of the lesions. Cooke and al [36] ha thus reported that the risk of mortality increased significantly if the time to treatment was longer than 2 hours $(p=0,028)$. Boyd [37] had insisted on the relationship between mortality and associated lesions.

\section{CONCLUSION}

Severe head injury is major public health problem. About half of the deaths from traumatic causes are due to head trauma. The essential aim of treatment is to prevent and/or limit the occurrence of secondary cerebral aggression factors of system origin. In recent years, the better understanding of the effect of therapeutics and the appearance of new agents have greatly simplified management in the majority of situations. This apparent ease should not make us lose sight of the very high mortality of severe head injury.

\section{REFERENCES}

1. Chesnut RM, Marshall LF. Management of severe head injury. In: Rapper AA, ed. Neurological and neurosurgical intensive care. New York: Raven Press, 1993; 203-46.

2. Maas A. Pathophysiology, monitoring and treatment of severe head injury. In: Vincent JL, ed. Yearbook of intensive care and emergency medicine (Springer Verlag, Brussels), 1993; 56478.

3. Mathé JP, Richard I, Rome J. (2005) Public health and severe head injury. Epidemiological and financial aspects, healthcare structures and channels. Ann Fr Anesth Réanim. (24), 688-694.
4. National Agency for Accreditation and health Evaluation. Management of severe head injury in the early phase. Ann Fr Anesth Réanim. 1999; (18), 1-172.

5. Sharma D, Monica B, Vavilala S. Preoperative management of adult traumatic brain injury. Anesthesiology Clin. 2012; (30), 333-346.

6. Alliez JR, Balan C, Leone M, Kaya JM, Reynier Y, Alliez B. Post-traumatic intracranial hematomas in the acute phase. Encycl. Méd. Chir (Elsevier Masson SAS, Paris), Neurologie. 2008; (17), 17-585-A-20.

7. Alliez JR, Hilal N, Kaya JM, Leone M, Reynier Y, Alliez B. Extraduraux intracranial hematomas: about 100 recent cases. Journal Neurochir. 2005; (54), 464-70.

8. Tiret L, Haushers E, Thiocoipe M, Garros B, Maurette P, Castel JP. The epidemiology of head trauma in Aquitaine, 1986: a community based study of hospital admissions and deaths. Int $\mathrm{J}$ epidemiol. 1990; (19), 133-40.

9. Aguemon AR, Padonou JL, Yevegnon SR, Hounkpe, Madougou S, Djagnikpo AK, Atehade D. Severe head injury in intensive care in Benin in 1998-2002. Ann Fr Anesth Réanim. 2005; 24(1): 36-9.

10. Servadei F. (1997) Prognostic factors in severely head injured adult patients with acute subdural hematomas. Acta Neurochir. (139), 279-85.

11. Rouxel JPM, Tazarourte K, Le Moigno S, Ract, Vigue B. Pre-hospital care of head trauma. Ann Fr Anesth Réanim. 2004; (23): 6-14.

12. Maleombho JP. Severe crania-cerebral trauma: medico-surgical aspect. Thesis : Méd : University of Abidjan. 2005.

13. Coulibaly M. Management of cranial trauma in the multi-purpose intensive care unit of the UHC of Kati. Thesis: Med : University of Bamako. 2010.

14. Hermo J. Head trauma in the Moroccan environment. Ann. Med. Chir. 1975; 6(1- 2), 3977.

15. Bande Y. Management of cranial trauma in the multi-purpose intensive care unit of the UHC of Bobo- Dioulasso. Thesis: Med: University of Bobo-Dioulasso. 2008.

16. Tentillier E, Ammirati C. Pre-hospital care of trauma head injury. Ann Fr Anesth Réanim. 2000; (19): 275-281.

17. Cissé N. Pre-operative management of head trauma in 81cases in the UHC of FANN. End of cycle memory: Med : University Cheik Anta Diop of Dakar. 2014.

18. Etori P. Management of cranial trauma in the multi-purpose intensive care unit of the UHC of Point G. Thesis: Med : University of Bamako. 1999.

19. Sieyamdji C. Investigation of 92 cases of severe head trauma recruited from the emergency surgical and intensive care units of the UHC 
Gabriel Touré of Bamako. Thesis: Méd : University of Bamako. 2007.

20. Traore M. Contribution to the study of trauma head injury in the UHC Gabriel Touré of Bamako. Thesis: Med: University of Bamako. 2003.

21. Hind EH. Secondary cerebral attacks of systemic origin in head trauma. Thesis: Méd : Medicine and pharmacy faculty of Casablanca. 2006; (140).

22. Bruder N, Gouvitsos F. Vascular filling in the first 24 hours after severe head injury. Ann Fr Anesth Réanim. 2000; (19), 316-325.

23. Nabouloum B. Trauma head injury aspects tomodensitométrie in the CHUSS of Bobo Dioulasso. Thesis: Med: University of Bobo Dioulasso. 2008.

24. Audibert G, Steinmann G, Charpentier C, Mertes PM. Management of the patient with acute intracranial hypertension. Ann Fr Anesth Réam. 2005; (24), 492-501.

25. Bruder N. Anesthesia and acute intracranial hypertension oncerebral edema. Anal Fr Anesth Réam. 2003; (22), 226-34.

26. Berte O. Become of severe head trauma victims inintensive care in the UHC Gabriel Touré of Bamako. Thesis: Med: Université de Bamako. 2009.

27. Damas F, Hans P. Management of trauma severe head injury during the first 24 hours. What specific therapies. Ann Fr Anesth Réanim. 2000; 19(4): 329.

28. Barone FC, Feuerstein GZ, White RF. Brain cooling during transient focal ischemia provides complete neuroprotection. Neurosc Biobehav Rev. 1997; (21), 31-44.

29. Bruder N, Ravussin P. Anesthesia in neurosurgery. Encycl Med Chir (Elsevier Masson SAS, Paris). 2005; (10), 36-613.

30. Mertes PM, Baumann A, Audiert G. Transfusion in neurosurgery. Encycl Med Chir (Elsevier Masson SAS, Paris). 2008; (15), 205-11.

31. Mendi J. Severe encephalic head trauma in the child. Thesis: Med : University Cheik Anta Diop of Dakar. 2002.

32. Coriat P. Medico-surgical emergency : anesthesia in intensive care today. Ed Arnettes, Paris. 1990.

33. Lescot T, Abdennour L, Degos V, Boch AL, Puybasset L. Management of severe traumatic brain injury. Presse medicale (Paris, France: 1983). 2007;36(7-8):1117-26.

34. Koné M, Niang B, Wade K. Become of trauma head injury victims with a Glasgow less than 8 , intubated and ventilated at the main hospital of Dakar. Ann Fr Anesth Réanim. 2004; (23), R190.

35. Tomta K, DjibrilMA, Mouzou T, Sama H, Chobli M. Severe trauma head injury in university hospital center of Tokoin in Lomé (Togo) from March $1^{\text {st }}$ to Augut $31^{\text {st }} 2008$. Journal of scientific research of the University of Lomé. 2011; 13:2.

36. Cooke RS, Mcnicholl BP, Byrnes DP. Use of the injury score in head injury. Pubme. 1995; (26), 339-400.

37. Boyd CR, Tolson MA, Copes WS. (1987). Evaluating trauma care: the triss method. J Traum. (27), 370-8. 